\title{
16
}

\section{The Community Model of Content Management}

\author{
Johannes Hummel and Ulrike Lechner \\ mcminstitute for Media and Communications Management, University of St. Gallen \\ Johannes.Hummel@unisg.ch and Ulrike.Lechner@unisg.ch
}

\begin{abstract}
Peer-to-peer architectures for sharing pieces of music illustrate how quickly consumers adopt novel structures - as long as they provide clear incentives. The services MP3.com, Napster, and gnutella are alternatives to the classical architecture of the value chain in which the music industry had a prominent role. We present a community model for content management and analyze system architectures, value chains, the relation between content and community management, and the trend towards peer-to-peer architectures. We argue that the traditional content is being increasingly embedded in a social, economic and organizational context and that therefore content management can hardly be separated from community management. We explain this comparing traditional and novel peer-to-peer content and community management of the music industry.
\end{abstract}

\section{MOTIVATION AND INTRODUCTION}

Information and communication technology does not only provide new kinds of content, but also new designs for the production, packaging, multiplying and distribution of it. As a consequence, novel business models occur where new actors are involved in various processes along the value chain.

This paper contributes to the discussion of the impact of technology on business models for content management. Our example is the music industry. This industry with the traditional offline industry and the novel services such as MP3.com, Napster.com, and gnutella is a prominent example of the role of technology in the change of the creation of economic value through new business models for content management. We focus on one particular business model, virtual communities, and argue that community and content management are inseparable in the novel services for content management. We present the community model for content management, discuss it and illustrate it with the novel structures in the music industry. 
This paper is organized as follows. First, we analyse the characteristics of content on the Internet as a digital product (Sect. 2). Second, we look at the role of communities regarding the management of content (Sect. 3). In this chapter, we describe types and functions of communities as business models and focus on the technology as a prerequisite for content management. In the fourth section (Sect. 4), we illustrate our description using the example of services and communities in the music industry. We close this paper with a short discussion of the findings (Sect. 5).

\section{CONTENT ON THE INTERNET}

The notion of content is closely related to the kind of medium that transfers it. In traditional one-way mass media content is typically a product of the media industry. Newspaper articles, television spots, sport coverage etc. are being produced, packed, multiplied, and distributed by the media industry. A piece of content, i.e., a television show or a newspaper article is in itself a sensible unit. The traditional communication channels assemble pieces of content according to their format and multiply and distribute the (packaged) content.

This is being changed through technology. Due to Internet and its digital technology content has a much broader meaning in the sense of an information good (Allen 1990). The characteristics of content on the Internet and its differences to content in the traditional media industry are shown briefly on four aspects:

1. Content is digital. Most contents are digital or have a digital counterpart. E.g., the mp3 format is a digital counterpart to analogous as well as other digital formats such as, e.g., CD-formate or disks and cassettes. There is both conventional and digital broadcasting and television. Digital contents can be distributed and processed with the means of information technology. As the digital technology becomes a commodity everybody can easily create, package or modify content. Moreover, digital contents are accessible to machines of all kind for processing this increases the availability of contents and makes the contents more valuable than conventional counterparts (Shapiro and Varian, 1999).

2. Content is linked. As the Internet can be seen as an electronic network, the content is embedded in and part of this network. Compare the isolated web pages to pages as part of a Web site or of an information system or online application. An isolated site or a single web-page is practically valueless - it will hardly be visited. Only if a page is linked, it is accessed through customers and becomes valuable. In many cases, the value of the content results from a direct link of information to transactions, e.g., through hyperlinks or from links between pure information on products and transaction services to buy those products (cf. (Shapiro and Varian, 1999)). Still, this content and its link structures need to be structured and organized (Stanoevska-Slabeva and Schmid, 2000). 
3. Content is interactive. As every participant is recipient and sender at the same time, the Internet allows interactivity in a much broader way than traditional media. There is traditional passive content, as e.g., the one on books, television, or broadcasting. Particular to the new media are interactive contents with some interaction between user and application or among users. Interactive contents may solve problems presented to them and adapt to users' needs. Therefore, the producer of content is not only the media industry, but also every participant in the Internet (Schmid 2000). This leads to the consequence that it changes over time with the media and the community interacting with the content.

4. Content is embedded in a social, economic and organizational environment. Individual content is sometimes very valuable for other participants. As the Internet does not only have the cultural function of information as traditional media, but also the economic function of commerce and the social function of community, this content spills over to these functions (cf. Sect. 3.2). E.g., in the Internet everybody can provide information about products. The experiences that consumers share are considered to be more trustworthy and valuable than information provided by producers. (Schubert, 1999; Schubert and Ginsburg, 2000; Hagel III and Armstrong, 1997)

The characteristics of content as shown above have several consequences on the whole value chain of the media industry. Not only the sources of content are much broader, as every participant is a potential creator and sender of content. But also as the Internet does not only allow one-to-many communication as the traditional media, but also many-to-one or many-to-many kind of communication, all steps of the value chain can be implemented following a new design. This leads to increasing competition on every stage of the value chain, as new business models occur for every part of the value chain, allowing new actors to participate and to manage the processes. As a consequence, the management of content is getting one of the most important functions to keep or get revenues from. The pure content, as produced typically by the media industry, is adorned with other contributions by the community. Here, content and the social environment of the community become inseparable. Moreover, with the novel peer-to-peer architectures, a transaction infrastructure for peers has emerged in the music sector. This article describes one of the most fascinating examples of this which has a deep impact on the business model for the media industry - the phenomenon of virtual communities and their peer-to-peer services as a possibility to manage and distribute music files through the consumers. 


\section{COMMUNITIES AS A MODEL FOR CONTENT MANAGEMENT ON THE INTERNET}

In this chapter, we describe virtual communities, their functions, and their role as a business model for community management. First, we take a closer look at the prerequisite for the development of these communities, the development of multidirectional communication, and peer-to-peer architectures as a consequence of the interactive technology of the Internet. On this basis, we describe virtual communities, their functions, and the business model "virtual community" in more detail.

\subsection{System architectures - infrastructures for communities}

The information and communication technology of the Internet provides platforms to create content as described above. On these platforms, interaction is part of the creation of content and of economic value. Three basic architectures for interaction can be differentiated (depicted in Figure. 1). In mass communication, the traditional model of the media industry, communication is unidirectional. Contents are being produced and distributed to the consumers through channels which allow hardly any feedback or consumer contribution. The possibility of easier and less costly interaction through the medium Internet changed the transactional model profoundly. In mass customization, communication channels are interactive content can be exchanged between consumer and producer/intermediary rather than transmitted from producers to consumers. A little feedback from the consumer enables the producer/intermediary to tailor the communication to the individual consumer. However, there is an information and communication asymmetry; typically, the producer has more information.
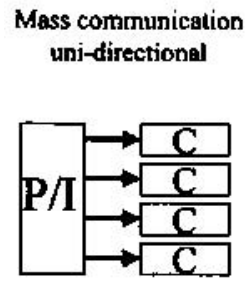
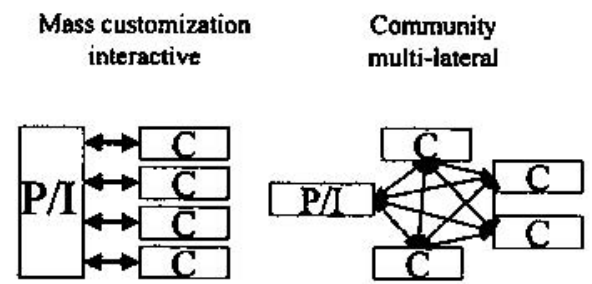

P/: Producer/Intermediary

C: Consumer

Exchange

Figure. 1 Interaction models

This asymmetry decreases in the community model as all interaction partners are able to communicate with each other. Computer science refers to this architecture as 
peer-to-peer. All members (of the community are able to participate in communication on an equal basis, i.e., as peers. Internet has a peer-to-peer architecture in the sense that every participant may initiate communication to anybody connected to this network. The service WWW allows everybody to publish and retrieve information from the Internet. Only recently, the interest in peer-to-peer architectures surged. Currently, the predominant transaction is the sharing of files (e.g., gnutella), and of storage or processing capacity (e.g., seti@ home).

Uni-directional, interactive and multi-lateral communication channels induce new architectures for the distribution of information. Characteristic of unidirectional communication is a client-server architecture with a powerful server that manages information, its flow, and weak clients. The position of the server is weakened and the position of the clients is strengthened in the interactive communication channel. The community model of computing induces an organization where all participants interact on an equal basis with respect to communication and computation.

Information and communication technology provides novel means to gather, process, distribute, and communicate information and content. Depending on their abilities for information processing and communication this technology allows in particular the consumers to become peers in the creation, sharing and management of common content. In business, such a communication design is often referred to as a "community". But what is a community all about?

\subsection{Communities and the role of content}

The term "virtual community" has established itself for communities in which communication is facilitated by electronic media, in particular, for communities where interaction takes place on the Internet. (Rheingold, 1993). Online community is a synonym for "virtual community". Over time various aspects of virtual or online communities have been discussed in literature: social, political, and economic aspects and the perception of virtual communities has changed over time from a social phenomenon to a valid business model (Hummel and Lechner, 2000).

The creation of economic value in this business model results especially from the content and knowledge, the participants bring into the community (Timmers, 1998). The members of a community may contribute to the creation of economic value with various kinds of contributions: information, product reviews, recommendations, pieces of music, files to be shared. The community contributes pieces of content similar to the contents produced by the media industry. Virtual communities, however, provide the social and economic environment that meets human needs and the contents that communities produce can hardly be separated from this context.

There are sociological, economic, and technological views on virtual communities. The first sociological definitions came from Taylor and Licklider who saw the community potential of electronic networks in 1968. They described their 
vision of a virtual community "...in most fields they will consist of geographically separated members, sometimes grouped in small clusters and sometimes working individually. They will be communities not of common location but of common interest... "(Licklider and Taylor, 1968).

Probably best known is the definition of Howard Rheingold (Rheingold, 1993). He defines virtual communities first as purely related to the Internet. From his point of view virtual communities are "...social aggregations that emerge from the Net when enough people carry on those public discussions long enough, with sufficient human feeling, to form webs of personal relationships in cyberspace" (Rheingold, 1993). Later, he also emphasizes the importance of the connection between real and virtual communities. Due to his experience with the virtual community "The well" (well.com), he sees communities as ".... a group of people who may or may not meet one another face to face, and who exchange words and ideas through the mediation of computer bulletin boards and networks" (Rheingold, 1994).

In a similar way, somehow seeming a little transfigured, argue Godwin and Jones. Godwin is of the opinion " ... but in cyberspace, increasingly, the dream is not just ,owning a house“ - it's living in the right neighborhood (Godwin, 1994)“. Jones even speaks of "virtual settlement (Jones, 1997)". Figallo is later stressing the meaning of common values writing "... according to that definition, members of a community feel a part of it. They form relationships and bonds of trust with other members and with you, the community host. Those relationships lead to exchanges and interactions that bring value to members" (Figallo, 1998).

From the view of computer-mediated-communication the most important elements of a virtual community are shared resources, common values, and reciprocal behavior. Whittaker et al. write in their definition “...members have a shared goal, interest, need,...engage in repeated, active participation,...have access to shared resources, reciprocity of information,... shared context of social conventions..." (Whittaker et al. 1997). Preece extends this view on the necessity of common rules ,....an online community consists of: People, who want to interact socially... policies ...that guide people's interactions (and) computer systems, to support and mediate social interaction..." (Preece, 2000).

Hagel and Armstrong were the first who broke with the view of virtual communities as sociological phenomenon (Hagel III and Armstrong, 1997). They see in virtual communities a business model which uses communication on the Internet to create electronic market places and to increase customer loyalty. Referring to Rheingold they define virtual communities “...but virtual communities are more than just a sociological phenomenon. What starts off as a group drawn together by common interests ends up as group with a critical mass of purchasing power, partly thanks to the fact that communities allow members to exchange information on such things as a product's price and quality"(Hagel III and Armstrong, 1997). Following (Timmers, 1998), we consider "Virtual Community" to be a business model in electronic markets distinguished by "The ultimate value of 
virtual communities is coming from the members (customers or partners) who add their information ...".

Virtual communities are socio-economic business models. Regarding economic functions, commercially-oriented virtual communities can contain, in general, all economic functions that are part of other Internet-intermediates.

Today, the business model of virtual communities is well differentiated. Figure 2 depicts the five kinds of commercially relevant communities and their content.

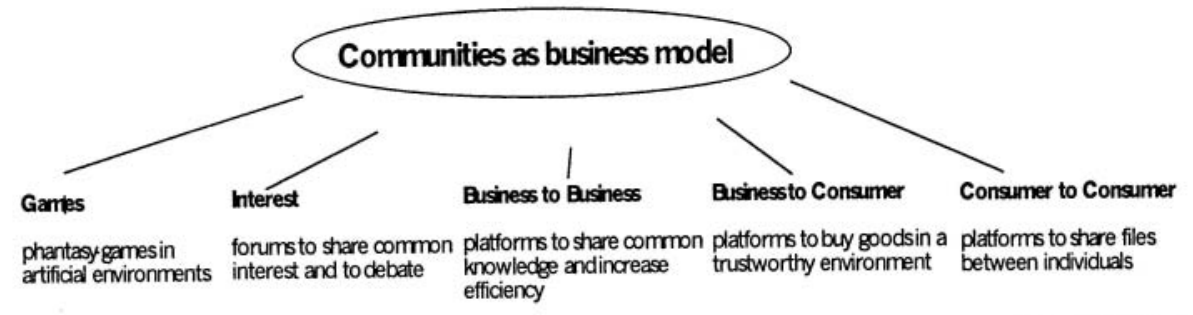

Communication

Transaction

Figure 2. Communities, their platforms and content

The purpose of game communities is playing interactive in artificial environments with other members. Communities of interest are forums to meet people and to debate with them about a common interest. In Business-to-Business communities people of the same profession meet each other, debate about business related issues, and make transactions regarding their business. Business-toConsumer communities create a trustworthy environment where consumers are more willing to buy from the shop(s), offering this community. Finally, in Consumer-toConsumer communities, individuals trade goods between each other without a commercial intermediary.

In all of these kinds of communities (depicted in Figure 2), content plays a mutual role. In game communities, participants create content in the way of "real" goods, as they explore resources, deal with each other or build their houses etc. In communities of interest, the participants use the forum to exchange thoughts or news. They bring in their own content and contribute to the existing content others brought in. In all transaction oriented communities from business-to-business over business-to-consumer to consumer-to-consumer we find two kinds of content. The first one is information which is shared or exchanged between all participants. In this way, content has the economic characteristics of an information good. The other ones are recommendations, reviews, and ratings of buyers and sellers and participants of chats etc. They help to create a social and economic environment to facilitate transactions through the building of trust, reducing complexity and 
transaction costs. Communities create extra value through combining both kinds of content.

Content has therefore different meanings in these business models. And it can be managed by all different participants of the community as well as by the technology itself (cf. for the services (Stanoevska-Slabeva and Schmid, 2000)). All participants can create or exchange content within the community. But also technology is playing a more and more important role regarding the creation of content. Think of the recommendation services of many online shops. The medium observes the transactions of participants, detects the social structure in terms of profiles and interests, and communicates the respective recommendations on which goods to buy. The exchange of information relevant for a customer segment is fully automated. Most likely such a communication does not meet the need for social relations and maybe this interaction does not foster trust. Similar to consumer contributed reviews the recommendation provides information about relevant and good products - based on the assumption that those eventually are being bought by more consumers.

In the following we illustrate at the example of the music industry what different kinds of this model occurred and how they change the value chain. These changes result in new possibilities to manage the most important content of this industry music files. It is accompanied by a switching of power from the traditional media industry to third party services and consumers.

\section{CONTENT MANAGEMENT IN THE MUSIC SECTOR}

In the past years a variety of new models for content management in the music industry have been implemented. MP3.com, Napster.com, and gnutella are examples for services for Online content management. In this section, we discuss their architectures for the creation of economic value through content management and explore the trend toward a community model for content management. We consider first the system architecture (Sect. 4.1.1) and then discuss the value chain with actors, roles, and the interaction on these architectures (Sect. 4.1.2). This first part is dedicated to the interaction infrastructure for community management with processes and interaction in content management. Then, we discuss the impact of content management to the social systems and the individual participating in the social system (Sect. 4.2). 


\subsection{Four models of content management}

Subsequently, we present four models and their system architectures (1) The traditional business models of the music industry (2) mp3.com as a client-server architecture (3) napster.com as a combination of client-server and peer-to-peer architecture and (4) gnutella as an example for a pure peer-to-peer architecture.

\subsubsection{System architectures}

The system architecture with components and interaction channels distinguish the technology of content management. The four architectures are depicted in Figure . We observe that the classic architecture of the traditional music industry with unidirectional communication channels is being succeeded by a client-server with bidirectional communication channels. The consumers and artists communicate with the service. MP3.com is an example for an implementation of this architecture. Napster.com exemplifies a combined client-server with peer-to-peer architecture. Further on, there are pure peer-to-peer architectures as, e.g., gnutella.

Within this development, a hierarchical model, where the music industry used to have a strong position is being accompanied by novel architectures that follow the community paradigm, i.e., with self-organization and symmetric positions of all actors. These architectures reflect the actors and their infrastructure for content management. They allow the actors to manage content in various ways throughout the whole value chain. Subsequently, we analyze the value chain and the processes of content management more in detail and compare again the various models.

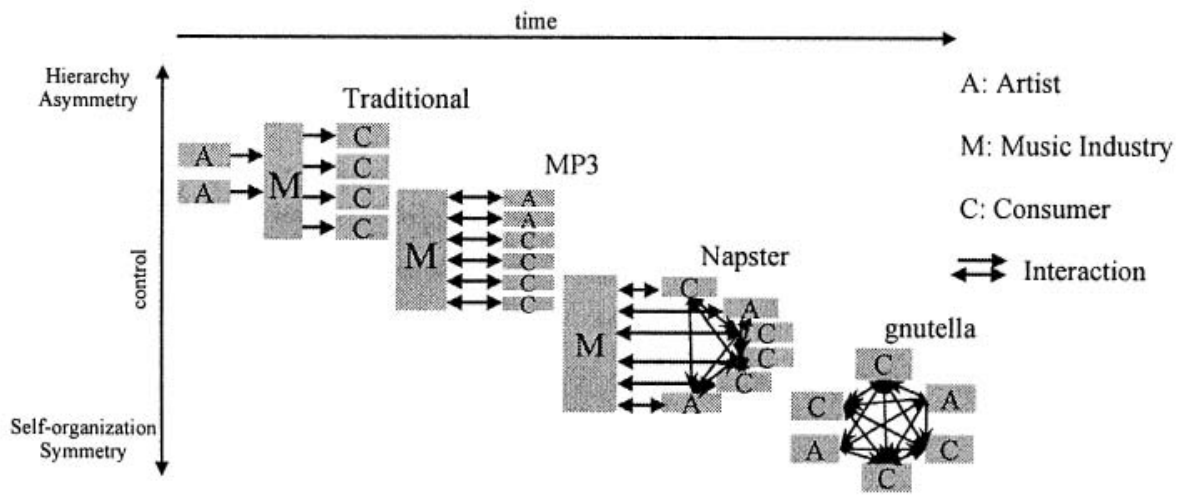

Figure 3. System architectures for content management in the music industry 


\subsubsection{Value Chain and Communication Design}

In terms of value creation we suggest to distinguish seven steps in the value chain and the respective communication model. In the traditional uni-directional value chain of the music industry as depicted in Figure (Music Ind.), the artist is responsible for the creative part, the idea. The contents are being established. Here, artists and music industry work together. Then, the product is packaged, marketed, multiplied, and distributed. The music industry occupies these stages in the creation of economic value. The role of the consumer consists just in buying the product.

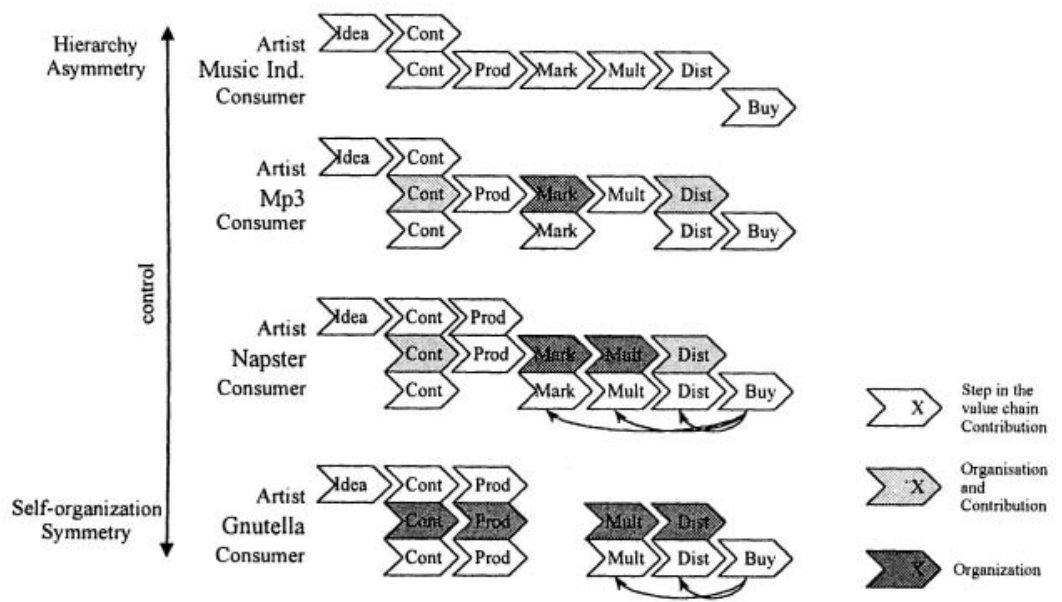

Figure 4. Value chains in the music industry

The novel services for content management - MP3, Napster and gnutella implement these steps in the value chain in a different ways. Each service is briefly introduced. Then, its value chain, as depicted in Figure is analyzed.

MP3.com considers itself to be an online repository of the users music files to facilitate access to those pieces of music everywhere on the Internet (mp3.com). Users upload pieces of music - or identify themselves in the so-called beamer services as owners of a carrier (CD) for some piece of music. Each user has its account to access the pieces of music online. Access to music is granted via Internet technology. MP3 provides (yet unknown) artists to publish a CD online and offers to produce, ship, and offer CDs on demand.

MP3 offers a recommendation service that points out artists and music and various services of community interaction. The server has files, registry and, because of the interaction services, all information about the consumers and the artists.

In terms of the value chain the consumers, service, and artists contribute mp3 files. The service of MP3 contributes the storage space for content and some means to structure and organize the access to content, e.g., in search engines and 
directories. The consumers take over the marketing through reviews and within a recommendation service for peer groups. Mp3.com just structures and organizes those contributions. They play an essential role for the distribution part of the value chain. MP3.com again just organizes this.

Thus, MP3 implements three steps in the value chain different from the music industry: the production of contents, the marketing, and the distribution. In all three cases, the consumers take over some role in contribution of contents - Mp3.com provides the means for structuring and organizing and allows for some interrelation between community and contents. However, only the step marketing follows a community architecture; the consumers interact following a community model.

Napster.com considers itself as "the world leading file sharing community" (napster.com). The server Napster.com offers a directory of lists of files to be shared and software to participate in the community. Each Napster client offers mp3 files of a dedicated folder on the hard-disk of the client to be shared to the community and allows to register all those files in the central directory, i.e. each client is client and server for sharing files. To search a file, the Napster client accesses the server. Swapping of files takes place following a peer-to-peer architecture. Napster.com has all the information necessary for community management. Every community member contributes content, storage facilities for files and digitized profiles.

In terms of the value chain depicted in Figure the service itself is involved in the marketing, multiplying, and distribution of the titles. The decision of a consumer to download (buy) a mp3 file influences the marketing implemented in a recommendation service. This dependency is represented as backwards arrows, Note that consumers themselves provide the resources for multiplication and distribution and trigger multiplication and distribution. This is also depicted as backwards arrows. Compared to the traditional model Napster implements four steps of the value chain in a novel way: production of contents, marketing, distribution, and multiplication. More steps of the value chain follow a community model - it is the community which contributes as peers to marketing, multiplication, distribution, and contents following in each step a community architecture. Moreover, Napster has features such as, e.g., buddy lists and allows for blocking certain users - such that the social aspects of a community and the content management within this community are more interrelated. Thus, Napster's architecture of the value chain is more peer-topeer and the social function of community spills over to content management.

Gnutella is a file-sharing application without any central structure. It is widely used to swap any kind of files. Gnutella clients form a self-organizing net of peers. Searching for files and swapping of files are exercised in a peer-to-peer architecture. A gnutella client is client and server for files. It offers all files in a dedicated directory to be shared on the net, swaps files, searches for files, routes messages and requests files. There is no central service.

Gnutella clients do not offer any community building services, as communication or recommendation services; there is no marketing in gnutella's 
value chain. The value chain of gnutella shows that - apart from marketing - all steps are taken over by the consumers. They contribute the content, do multiplication and distribution (by their decisions to upload and download music). The service just facilitates all these interactions of the consumers.

In the development of the value chains, we see that various steps are implemented in a peer-to-peer architecture and that the pure content management of the traditional music industry gets interrelated with the community and its function. The contents in the community systems such as, e.g., Napster or gnutella is inseparable from the community: it is the community that contributes contents, marketing, multiplication, and distribution - the server only facilitates and structures the interaction.

Note however, that those value chains can hardly be considered isolated. The marketing done by the music industry plays an important role in all value chains - in all online services users need to know which titles they are interested in. This knowledge and the interest profiles are the basis for the recommendation services.

The developments in this sector are technology driven, but the consumer has an important role: the clear incentives motivate consumers to adopt these novel technologies and services. Since content and community and content management and community management are becoming increasingly inseparable one may ask how a community evolves using such a service and how individual strategy and community welfare relate to one another. This is discussed in the following section.

\subsection{Member and community management}

As shown above, all these communities rely on a variety of communication technology that enables various ways of interaction. Common to all these technologies is the fact that they are network technologies. Therefore one can expect that these business models are driven by network effects which are due to system feedbacks. Positive feedback describes the effect that the strong get stronger and the weak get weaker. Conversely, negative feedback describes that the strong get weaker and the weak get stronger. When the value of a good or service to one user depends on how many other users there are economists say that this product exhibits network externalities or network effects (Shapiro and Varian, 1999). Network effects are often the result of positive feedback effects.

As information and communications technology is changing from a technology for information processing to a communication technology these network effects play a more and more important role. Hagel and Armstrong refer to positive network effects as a major driver for the development of communities (Hagel III and Armstrong, 1997). On the first glance, all the four models described above seem to be the same regarding network effects. The more users such a service has, the more contents it is going to have and the more attractive it becomes. A more detailed view on the different technologies and on particular aspects shows however that some of 
the these technologies do also have specific negative feedbacks. Subsequently, we discuss the relation between a single user's contribution to the network and the effect that this has for its benefit from the network. One would expect that the architectures that resemble communication networks most closely, i.e. the architectures most closely to peer-to-peer architectures, are more likely to exhibit positive feedback effects. We argue that in fact these architectures display negative feedback. In this section, we explore the network effects and consumer benefit for the stages of the value chain of Sect. 4.1.2 contents, marketing, multiplication and distribution.

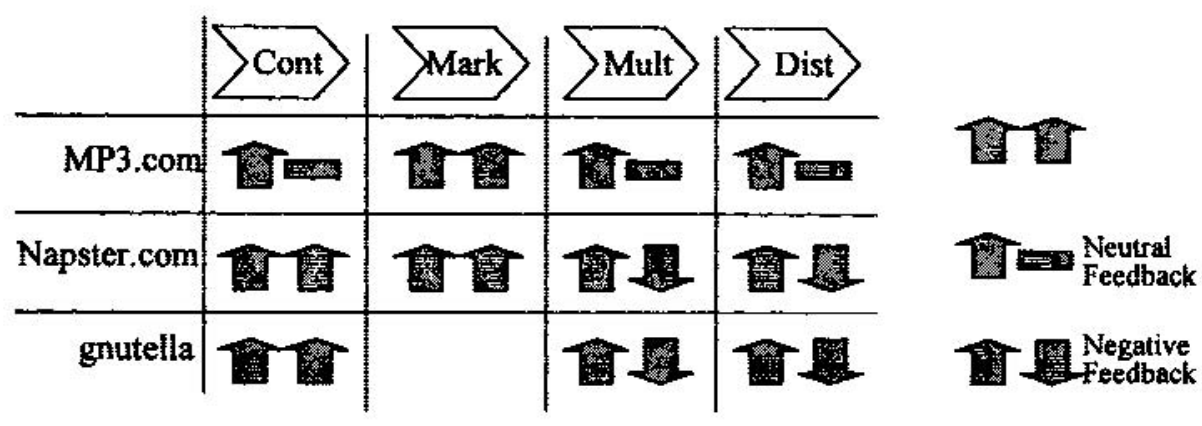

Figure 5. Feedback effects

Let us consider content and the correlation between the files a user contributes and the benefit a user has from contributing. The consumer has at MP3.com a neutral and at Napster.com and Gnutella positive feedback through an increase of the number of contributed files. All contents a user contributes are stored and available online such that the single user benefits from the storage capacity and the reliability of the network. This is some (relatively small) benefit that exceeds the mere increase of available files by increasing the number of files contributed. At MP3 the user basically has exactly those files at his disposal that she stores online the increase in contribution equals the benefit, i.e. there is neutral feedback. Concerning marketing the important features are recommendation services. Those services improve with the number of transactions a single user and the whole community perform. This means a positive feedback at MP3 and Napster. Another relevant feature at Napster.com is the service that allows a user to govern who may download files from her computer. Many users are willing to share files only with those who also contribute and the service allows to block unwanted users from download. Both MP3 and Napster have here a positive feedback - the more information and files a user contributes - the better. In gnutella there is no such benefit, since there is no marketing. 
In multiplication and distribution the feedback is either neutral or negative. On Napster and gnutella users do not only share files but also storage capacity and bandwidth. The one who contributes files shares his bandwidth with the users that download files from his computer. The consequence is a negative feedback for the individual user. The more and more popular files an individual offers, the more of his bandwidth is consumed by the ones downloading the files. Thus, at Napster and gnutella there is a negative feedback at this step of the value chain. Empirical studies show the asymmetry in contribution and the effect that people lie in terms of their speed of connection to the Internet such that they are not the ones who are selected as servers for a download (Adar and Huberman, 2000). At MP3, all users share the connection to the server, but not the "last mile". At this service the contributions do not inflict multiplication and distribution - we regard them to be neutral.

To sum up this analysis. Network effects do not apply to all three file sharing services. Moreover it is contribution of content that makes the least difference - the users have little positive or neutral feedback there. We assume that users of the services weigh the benefit that they have from the service as a storage device much lower than the negative feedback from distribution and multiplication. The disadvantage of sharing bandwidth with other users is clear for the one who contributes files. Thus, negative feedback in multiplication and distribution applying at Napster and gnutella outweights the positive or neutral feedback in contribution. The growth rate at Napster is high - a clear indicator for positive feedback and network effects. This again is then most likely due to the positive feedback of Napster in marketing. Moreover, Napster provides means for the management of the negative feedback effect in multiplication/distribution - a user can block users (typically the ones who do not contribute themselves) from downloading. Thus, marketing with the recommendation services display positive feedback - blocking users helps to manage the negative feedback. Marketing and this management of relations establish the connection between the contents and the social environment. It is the social environment and its the relation to content that differentiates the services and feedback effects.

This case illustrates that the management of those contents that used to be the product of the media industry does not distinguish the different services for content management. It is the linkage between "pure" content and user contributed content and between content and the social environment that distinguishes the services. Hereby, content management and management of the community are inseparably interrelated and pieces of music alone do not make up the value of a network. The pure content is embedded in the social structure of the community with profiles, recommendations reviews, and personal relations. It is this social structure and the management of the community that distinguishes the services - not the mp3 files. 


\section{COMMUNITIES AS TOOL FOR CONSUMER CONTROL}

The new characteristics of content in the Internet has at least two consequences for the economic situation along the value chain. First, the management of content gets more and more important for the creation of value. Second, the new business models allow various new and different ways of managing this content which undermine obviously the power of the traditional players in the markets. Communities and peer-to-peer architectures lead to more similarity in terms of contribution and power and between the different actors along the value chain. As the example of the music industry shows, there is a rapid development of various business models in this field which give more influence on the management of content to the consumers. The fact that content is digital allows more people to contribute. The fact that content needs to be linked allows for different kinds of contents to be joined and new organizational forms of the contents. The fact that it is interactive allows for new ways of interaction among all actors in the value creation. Most important, however, is that content becomes inseparable from the social, political, and organizational environment. The community attaches its structure to the content, e.g., in reviews, recommendations or personal relations and the content management influences the social, economic, and organizational structure of any community. Particular to the novel systems is that the community with authors, actors and consumers that structure and organize the transactions takes over the power in those systems.

These developments are driven by technology and the consumers. None of this models is older than two years, but they have already become very popular. But the novel architectures support more than "communication and information" - they are the basis for transaction and organize the community to take over a number of functions the media industry or intermediaries used to occupy. The socio-economic business model "community" gains a novel relevance in various application fields. The music sector and in particular the alliance of Napster and Bertelsmann and all the legal approaches to stop the developments illustrate that novel, originally technology driven designs may change a value chain and a whole industrial sector.

Acknowledgements. We are indebted to the anonymous referees for valuable comments. We are also indebted to B. Buchet for proofreading. The work of Ulrike Lechner is sponsored by the Swiss National Funds in an endowed professorship. 


\section{REFERENCE LIST}

Adar, E. and Huberman, B. (2000) Freeriding on Gnutella. Firstmonday 5, Figallo, C. (1998) Hosting Web Communities: Building Relationships, Increasing Customer Loyality, and Maintaining a Competitive Edge, Wiley Computer Publishing.

Godwin, M. (1994) Nine Principles for Making Virtual Communities. Wired

Haertsch, P. (2000) Wettbewerbsstrategien für Electronic Commerce, Josef Eul Verlag.

Hagel III, J. and Armstrong, A. (1997) Net Gain: Expanding markets through virtual communities,

Hummel, J. and Lechner, U. (2001) Communities - The role of technology. In: European Conference on Information Systems (ECIS 2001). To appear. 2001.

Jones, Q. (1997) Virtual Communities, Virtual Settlement \& Cyber-Archaelogy: A Theoretical Outline. JCMC 3,

Levine, R., Locke, C., Searls, D. and Weinberger, D. (1999) The cluetrain manifesto. The end of business as usual, Perseus Books.

Licklider, J.C.R. and Taylor, W. (1968) The computer as a Communication Device. Science and Technology 21-40.

Preece, J. (2000) Online Communities, 1 edn. New York:

Rheingold, H. (1994) A Slice of Life in my virtual community. In: Haramsin, L.M., (Ed.)

Rheingold, H. (1993) The virtual community: homesteading on the electronic frontier, Addison-Wesley.

Schmid, B.F. (2000) Was is new in the digital economy? EM-The Int. Journal of Electronic Markets and Business Media, 11( 1).

Schubert, P. (1999) Virtuelle Transaktionsgemeinschaften im Electronic Commerce: Management, Marketing und Soziale Umwelt., Josef Eul Verlag.

Schubert, P. and Ginsburg, M. (2000) Virtual Communities of Transaction: The Role of Personalization in Electronic Commerce. EM - Electronic Markets. The International Journal of Electronic Markets and Business Media, 10(4).

Shapiro, C. and Varian, H. (1999) Information Rules: A Strategic Guide to the Network Economy, Harvard Business School.

Stanoevska-Slabeva, K. and Schmid, B.F. (2000) Community Supporting Platforms. EM-The Int. Journal of Electronic Markets and Business Media, 10(4).

Timmers, P. (1998) Business Models for Electronic Markets. EM - Electronic Markets. The International Journal of Electronic Markets and Business Media 8(3).

Whittaker, Issacs and O'Day (1997) Widening the web. Workshop report on the theory and practice of physical and Network communities. Report from ACM CHI. 